\title{
TO EVALUATE CARDIAC AUTONOMIC NERVOUS SYSTEM FUNCTIONS IN PATIENTS WITH RHEUMATOID ARTHRITIS
}

\author{
Sidhu Manusmriti ${ }^{1 *}$, Salwan Shalini $^{2}$, Walia Lily ${ }^{3}$, Puri Sandeep ${ }^{4}$ \\ ${ }^{1}$ Assistant professor, Department of physiology, BJS Dental College, Ludhiana, Punjab, India \\ ${ }^{2}$ Associate professor, Department of pharmacology, PIMS, Garha Road Jalandhar, Punjab, India \\ ${ }^{3}$ Professor and Head, Department of physiology, MMIMSR, Solan, HP, India \\ ${ }^{4}$ Professor and Head Department of Medicine, DMC, Ludhiana, India \\ *Corresponding Author: Email-drmanusmriti77@gmail.com
}

Received 30 Nov 2014; Review Completed 07 Jan 2015; Accepted 07 Jan 2015, Available online 15 Jan 2015

\begin{abstract}
Aim: To evaluate cardiac autonomic nervous system functions in patients with rheumatoid arthritis.

Material snd Methods: The present study was carried out on both males and females of mean age group $44 \pm 12$ years to study autonomic functions in RA. All parameters were recorded and studied on 35 volunteers, out of which 25 were diagnosed with RA and 10 were healthy individuals which served as controls. The cardiac functions were evaluated by six non-invasive standardized tests consisting of 30:15 ratio, standing / lying ratio, expiration / inspiration ratio, valsalva ratio, blood pressure response to standing, blood pressure response to valsalva maneuver and hand grip test.The tests were carried out on patient (in and out door) in department of Medicine, at DMC \& H by using cardiofax Machine (Medicarid systems).Details of history and examination were recorded on special proforma.

Results: In the present study standing to lying ratio $(\mathrm{p} \leq 0.001)$,Expiration to inspiration ratio ( $\mathrm{p}<0.01)$ both indicative of parasympathetic function were significantly less in RA patients as compared to control indicating an impaired vagal function in study group.On the blood pressure response to standing, the decrease in diastolic blood pressure was significant $(\mathrm{P}<0.01)$ in study group as compared to control which is indicative of hypofunctional sympathetic ANS.

Conclusions: There is cardiac autonomic nervous system dysfunction (both sympathetic and parasympathetic) in the patients with Rheumatoid arthritis when compared to control.Autonomic function tests can help in predicting cardio vascular risk in Rheumatoid Arthritis patients.
\end{abstract}

\section{INTRODUCTION}

Rheumatoid arthritis is the commonest inflammatory arthritis occurring throughout the world. ${ }^{1}$ Neuropathy is one the most common extra - articular manifestations of this disease which manifests as primary sensory peripheral neuropathy, the etiology of which is not clear ,may be vasculitis. ${ }^{2}$ CNS regulatory pathways may be perturbed in RA in several ways. An inappropriately low HPA-axis response, whether due to blunted hypothalamic, pituitary or adrenal response, or resistance at the level of the glucocorticoid receptors, predisposed to susceptibility to exacerbated auto immune/ inflammatory disease. ${ }^{3}$ Sympathetic and parasympathetic involvement have been described in primary and secondary vasculitis processes, as in systemic vasculitis processes like: SLE, RA. ${ }^{4}$ According to studies conducted on western population, sympathetic nervous system activity is significantly elevated in RA patients. $^{5}$
In order to evaluate autonomic functions besides clinical symptomatology, objective assessment can be done by noninvasive well validated clinical tests. These tests are of immense value to diagnose the presence and to demonstrate the distribution of autonomic failure. ${ }^{6}$ These tests are heart rate response to standing, blood pressure response to change in posture, variation in heart rate with respiration, valsalva ratio, and isometric exercise test. There is dearth of literature for comprehensive studies in relation to presence of autonomic disturbance in rheumatoid arthritis. Since vasculitis is an extra-articular manifestation of rheumatoid arthritis and it is known to cause involvement of peripheral nerves leading to mononeuritis multiplex, it is conceivable that it may lead to involvement of small unmyelinated type $\mathrm{C}$, postganglionic autonomic nervous system. In the present study autonomic dysfunctions, if any, have been evaluated by a battery of six noninvasive cardiovascular reflex tests. 


\section{MATERIALS AND METHODS}

\section{Study Design}

The present study was carried out on both males and females of mean age group $44 \pm 12$ years to study autonomic functions in RA. All parameters were recorded and studied on total of 35 volunteers, out of which 25 were diagnosed with RA, by using criteria developed by American College of Rheumatology ${ }^{7}$ and 10 were healthy individualsand not on any medication, served as controls. The tests were carried out on patients (in and out door) in department of Medicine, at DMC \& $\mathrm{H}$ by using cardiofax Machine (Medicarid systems). To exclude any systemic or related disease, special care was taken not to miss any relevant history. Details of history and examination were recorded on special Proforma. Patients were examined for signs and symptoms of possible Autonomic Nervous System (ANS) dysfunctions including orthostatic hypotension (lightheadedness, blurred vision, sensation of weakness and unsteadiness, fainting or syncope on standing), perspiration, palpitations and Raynaud's phenomenon. The written consent of subjects was taken on inform consent form in local language.

\section{Inclusion criteria:}

Patients of either sex in the age range of $44 \pm 12$ years diagnosed with RA according to criteria developed by American College of Rheumatology ${ }^{7}$ were included in the study.

\section{Exclusion criteria:}

Patients with hemoglobin $<10 \mathrm{gm} \%$,patients with positive pregnancy test, patients suffering from disorders $\&$ interfering with the Autonomic nervous system like Diabetes mellitus, renal and Liver diseases and Parkinson's disease, any CVS disease - hypertension, Ischemic heart disease and Congestive heart failure, patients suffering from Neurological diseases like multiple sclerosis polyneuropathy or GuilliainBarre syndrome and patients treated with drugs that interfere with the Autonomic nervous system including anti hypertensives, diuretics, adrenergic drugs, antiarrhythmic, sedative-hypnotics and anti-epileptic drugs were excluded from the study.

\section{CRITERIA FOR EVALUATION}

To evaluate cardiac Parasympathetic nervous system functions, testsperformed were:

1. 30:15 Ratio (Heart rate response to immediate standing)

Subject was made to lie comfortably and ECG was recorded in lead II continuously on cardio fax for $30 \mathrm{sec}$. The subject was then asked to stand up unaided, the point when the patient standing was marked on ECG. The ECG was recorded for 1 minute from standing. The $\mathrm{R}-\mathrm{R}$ intervals were measured on ECG with a ruler. The 30:15 ratios was calculated by taking ratio of longest $\mathrm{R}$ $\mathrm{R}$ interval at beat 30 and shortest R-R interval at beat 15 after standing. A 30:15 ratio of 1.00 was taken as normal and value of $<1.00$ was considered abnormal. ${ }^{8}$

$$
30: 15 \text { ratio }=\frac{\mathrm{R}-\mathrm{R} \text { interval at beat } 30}{R-R \text { interval at beat } 15}
$$

2. Standing / Lying Ratio (Heart rate response to lying down)

Subject was made to stand quietly and then lie down without any support while continuous ECG was recorded from 20 beats before to 60 beats after lyingdown. The point at which subject started to lie down was marked. $\mathrm{S} / \mathrm{L}$ ratio was calculated as longest R-R interval during 5 beats before lying down to shortest R-R interval during 10 beats after lying down ${ }^{9} \mathrm{~S} / \mathrm{L}$ is test for parasympathetic damage. An S/L ratio of $>1$ was taken as abnormal. An $\mathrm{S} / \mathrm{L}$ ratio of $<1$ was taken abnormal. ${ }^{10}$

\section{$\mathrm{S} / \mathrm{L}$ ratio $=\frac{\text { Longest } \mathrm{RR} \text { interval during } 5 \text { beats before ly ing down }}{\text { Shortest } \mathrm{R}-\mathrm{R} \text { interval during } 10 \text { beats after ly ing down }}$}

\section{Expiration/inspiration Ratio}

Subject was asked to breathe deeply at rate of six breaths per minute. A standard ECG recording was taken during deep inspiration and expiration. Variation in heart rate was calculated as ratio of longest $\mathrm{R}-\mathrm{R}$ interval during expiration to shortest R-R interval during inspiration. ${ }^{11} \mathrm{~A}$ value of 1.20 or higher was taken as normal. ${ }^{12}$

Expiration/Inspiration ratio $=$

Longest R-R interval during expiration

Shortest $\mathrm{R}-\mathrm{R}$ interval during inspiration

\section{Valsalva ratio}

Subject was made to perform valsalva maneuver for 15 seconds by blowing against closed glottis through a mouth piece attached to sphygmomanometer and maintained an expiratory pressure of $40 \mathrm{~mm}$ of $\mathrm{Hg}$ for 15 sec. ECG was recorded during the maneuver (strain period, $15 \mathrm{sec}$ ) and for fifteen seconds after release of pressure. Thevalsalva ratio was calculated as the ratio of longest R-R interval after maneuver to shorter R-R interval during maneuver. Value $>1.21$ was taken as normal and value $<1.21$ was considered abnormal. ${ }^{13}$ 
To evaluate cardiac sympathetic nervous system functions, tests performed were:

\section{B.P response to Standing}

The subject was asked to stand from supine position within 3-4 sec. and to remain motionless. Blood pressure was recorded in 30 second interval. Difference between readings of SBP recorded in lying position and then after standing was calculated. Normal response is taken as $<10 \mathrm{mmHg}$ fall in blood pressure. A fall in blood pressure $>20-30 \mathrm{~mm} \mathrm{Hg}$ of systolic ${ }^{\mathbf{1 4}}$ and $>20 \mathrm{~mm} \mathrm{Hg}$ diastolic (AAS \& AAN, 1996) is taken abnormal.

\section{B.P response to Valsalva maneuver \\ 3. B.P response to sustained hand grip}

Details of procedure were explained and baseline BP was recorded with the help of sphygmomanometer. The subject was asked to hold the hand grip dynamometer in right hand and was instructed to compress the hands with maximum effort. The tension developed was measured, 3 readings were taken and mean of three readings was taken as Tmaxmaximal isometric tension. Then the subject was asked to maintain a pressure of $30 \%$ of Tmax for 5 min. During procedure, B P was recorded every $30 \mathrm{sec}$ with the help of syhygmomanometer on the non-exercising arm. ${ }^{15}$ The rise in diastole BP at the point just before the release of hand grip was taken as index of response to hand grip test. The value of more than 15 $\mathrm{mm} \mathrm{Hg}$ rise in diastolic $\mathrm{BP}$ was taken as normal response, $11-15 \mathrm{~mm} \mathrm{Hg}$ as borderline and $10 \mathrm{~mm} \mathrm{Hg}$ or less as abnormal indicating sympathetic insufficiency. ${ }^{(16)}$ The heart rate in all these tests was calculated from $\mathrm{R}$ $\mathrm{R}$ interval in beats/min by continuous recording of ECG in lead II on cardio fax machine. Blood pressure recording (both systolic and diastolic) in $\mathrm{mmHg}$ was done by standard sphygmomanometer. Before every test, heart rate was allowed to come down to normal resting level (Basal).

\section{Statistical Analysis}

Data was compiled and expressed as ratio and mean percentage changes. Student's unpaired t-test was applied to compare the two groups.

\section{Observation and Results}

Present study was carried out on 35 subjects. The subjects were grouped into Study group (Group - A) and Control group (Group - B). The study group (Group - A) consisted of 25 subjects diagnosed with rheumatoid arthritis on basis of criteria developed by American College of Rheumatology. The control group (Group B) consisted of 10 diseases free healthy subjects not on any medication (so as to explain normal changes). The demographic profile was recorded by their age and sex.

Table 1

\begin{tabular}{|l|l|l|l|l|l|}
\hline & MeanHR $\underline{\text { SD }}$ & Mean 30:15 ratio \pm SD & $\begin{array}{l}\text { MeanS/L Ratio } \\
+ \text { SD }\end{array}$ & $\begin{array}{l}\text { Mean Exp/Insp } \\
\text { Ratio }+ \text { SD }\end{array}$ & $\begin{array}{l}\text { Mean Valsalva } \\
\text { Ratio } \pm \text { SD }\end{array}$ \\
\hline Group A & $76.48 \pm 9.11$ & $1.02 \pm 0.24$ & $0.95 \pm 0.13$ & $1.16 \pm 0.13$ & $1.29 \pm 0.36$ \\
\hline Group B & $75.9 \pm 6.79$ & $1.10 \pm 0.12$ & $1.10 \pm 0.08$ & $1.28 \pm 0.14$ & $1.31 \pm 0.24$ \\
\hline P value & $>0.01(\mathrm{NS})$ & $>0.01(\mathrm{NS})$ & $<0.001(\mathrm{HS})$ & $\leq 0.01(\mathrm{~S})$ & $>0.01(\mathrm{NS})$ \\
\hline
\end{tabular}

HR- Heart Rate, S/L-Standing/Lying, Exp/Insp-Expiration/Inspiration, S- Significant, HS- Highly Significant, NS- Not Significant

Table 2

\begin{tabular}{|c|c|c|c|c|c|c|}
\hline & $\begin{array}{lr}\text { Mean \% change } \\
\text { in SBP from } \\
\text { lying } & \text { to } \\
\text { standing } & \\
\text { position } & \end{array}$ & $\begin{array}{l}\text { Mean } \% \\
\text { change in DBP } \\
\text { from lying to } \\
\text { standing } \\
\text { position }\end{array}$ & $\begin{array}{l}\text { Mean } \% \\
\text { change in SBP } \\
\text { from resting to } \\
\text { valsalva }\end{array}$ & $\begin{array}{lr}\text { Mean } & \% \\
\text { change } & \text { in } \\
\text { DBP } & \text { from } \\
\text { resting } & \text { to } \\
\text { valsalva } & \\
\end{array}$ & $\begin{array}{l}\text { Mean } \% \\
\text { change in SBP } \\
\text { from resting to } \\
\text { after hand grip } \\
\text { test }\end{array}$ & $\begin{array}{l}\text { Mean \% change } \\
\text { in DBP from } \\
\text { resting to after } \\
\text { hand grip test }\end{array}$ \\
\hline Group A & $4.38 \pm 2.82$ & $2.52 \pm 3.61$ & $17.46 \pm 14.4$ & $15.55 \pm 11.97$ & $8.36 \pm 5.70$ & $9.05 \pm 5.76$ \\
\hline Group B & $5.09 \pm 3.84$ & $5.87 \pm 2.81$ & $14.49 \pm 5.2$ & $12.08 \pm 2.36$ & $11.21 \pm 6.61$ & $13.53 \pm 6.14$ \\
\hline $\mathrm{P}$ value & $>0.01(\mathrm{NS})$ & $\leq 0.01(\mathrm{~S})$ & $>0.01(\mathrm{NS})$ & $>0.01(\mathrm{NS})$ & $>0.01(\mathrm{NS})$ & $\leq 0.01(\mathrm{~S})$ \\
\hline
\end{tabular}

DBP-Diastolic Blood Pressure, SBP-Systolic Blood Pressure, S- Significant, HS- Highly Significant, NS- Not Significant

\section{DISCUSSION}

Autonomic dysfunction has been reported in patients with rheumatoid arthritis and systemic lupus erythematosus like connective tissue disorders, cause of which may be vasculitis of vasa nervoram and secondary amyloidosis.An immune component can also be responsible for autonomic dysfunction ${ }^{17}$. To assess the autonomic nervous system functions in patients with Rheumatoid Arthritis, 35 subjects were divided into two groups, the study group consisted of 25 subjects diagnosed with Rheumatoid Arthritis, using criteria (c) 2011-14, JDDT. All Rights Reserved developed by American college of Rheumatology ${ }^{7}$ and control group consisted of 10 healthy individuals. The cardiac functions were evaluated by six non-invasive standardized tests which consisted of 30:15 ratio, standing / lying ratio, expiration / inspiration ratio, valsalva ratio, blood pressure response to standing, blood pressure response to valsalva maneuver and hand grip test. These tests evaluated the sympathetic and parasympathetic divisions of ANS.The results of tests were compared with the control by using unpaired t-test. 
a) In the present study standing to lying ratio $(\mathrm{p} \leq 0.001)$, expiration to inspiration ratio $(\mathrm{p}<0.01)$ both indicative of parasympathetic function were significantly less as compared to control. This decrease indicated an impaired vagal function in study group. The 30:15 ratio, valsalva maneuver demonstrated a slightly decrease but was statistically non-significant in the patients with Rheumatoid Arthritis as compared to control ( $p>0.05)$.(Table 1)

b) On the blood pressure response to standing. The change in diastolic blood pressure was significantly $(\mathrm{P}<0.01)$ lower in study group as compared to control. (Table 2) This result is indicative of hypofunctional sympathetic ANS leading to unaltered or decreased peripheral resistance which leads to decrease in the percentage change of diastolic blood pressure.

\section{REFERENCES}

1. Bax M, van Heemst J, Huizinga TW, Toes RE. Genetics of RA: what have we learned?Immunogenetics.2011; 23:459-66

2. Lipsky P E. Rheumatoid Arthritis In: Braunwald E, Fauci A S, Kasper D L, Hauser S L, Longo D L eds. Harrison's Principles of Internal Medicine. $15^{\text {th }}$ Edition. New York: McGraw Hill; 2003: 1928-29.

3. Eskandari F, Webster J I, Sternberg E M. Neural immune pathways and their connection to inflammatory diseases. $J$ Neuroimmunol. 2006 Mar; 172 (1-2): 38-58.

4. James P, Dyek B, Ted M Burns, Gregory A. Schauplin: Vasculitic Neuropathies. NeurolClin2007; 25: 89-113.

5. Dekkers JC, Geenen R, Godaert GL, Bijlsma JW, van Doornen LJ. Elevated sympathetic nervous system activity in patients with recently diagnosed rheumatoid arthritis with active disease. Clin Exp Rheumatol. 2004; 22:63-70.

6. Low P A, Vernino S, Suarez G. Autonomic dysfunction in peripheral nerve disease. Muscle Nerve 2003 Jun; 27(6): 64661.

7. Arnett F C Edworthy S M, Bloch D A, et al. The American Rheumatoid Association 1987 revised criteria for the classification of rheumatoid arthritis. Arthritis Rheum. 1998; 31: 315-24.

8. Ewing D J, Campell I W, Murray A, Neilson J M, Clarkes B F. Immediate heart rate response to standing simple test for autonomic neuropathy in diabetes. $\mathrm{Br}$ Med J 1978; 1: 145147.

\section{CONCLUSION}

Study has confirmed the presence of significant cardiac autonomic nervous system dysfunction (both sympathetic and parasympathetic) in the patients with Rheumatoid arthritis when compared to control. Hence, inclusion of cardiovascular autonomic function tests in routine clinical examination may be helpful in early detection of autonomic dysfunction in this disease.A diagnosis of autonomic disturbance cannot be substantiated on the basis of the results of a single test. For making a definite diagnosis of autonomic dysfunction, abnormal values in at least two tests is conventionally accepted ${ }^{\mathbf{1 3}}$ subjects who have only 1 test abnormal and with the other tests at lower limits of normal ranges have early or borderline damage. Further useful and comprehensive information about autonomic function might be extracted from global evaluation of all tests performed.

9. Ahuja M V, Kumar Ramesh. Basal autonomic functions in males and females. Indian J PhysiolPharmacol. 1999; 43(4): $521-522$.

10. Jain A K. Manual of practical physiology for MBBS. $1^{\text {st }}$ Edition. New Delhi, Arya Publications 2003: 248-252.

11. Sandroni P. Testing the autonomic nervous system. Technical Corner from IASP (International Association for Study of Paid) Newsletter. 1998 Nov/Dec. 1-10.

12. Marya R K. Medical Physiology. $2^{\text {nd }}$ edition. New Delhi: CBS; 2003: 302-303.

13. Neumann $\mathrm{C}$ and Schmid H. Standardization of a computerized method for calculating autonomic function test responses in healthy subjects and patients with diabetes Mellitis. Brazilian Journal of Medical and Biological Research. 1997; 30(2): 1997-205.

14. Raclene E Maser. Autonomic neuropathy: Patients care. Diabetes Spectrum. 1998: 11(4): 224-227.

15. Jain A K. Manual of Practical physiology for MBBS. $2^{\text {nd }}$ Edition. New Delhi: Arya Publications; 2007: 283-284.

16. Ghai C L. A textbook of practical physiology. $7^{\text {th }}$ Edition. New Delhi: Jaypee Brothers; 2007: 245.

17. Saraswathi PV, Neelambikai N, Mahesh A, GovindarajanK.Indian J Physiol Pharmacol.2013 JanMarch;57(1):23-30. 